\title{
The role of biotin and oxamate in the carboxyl transferase reaction of pyruvate carboxylase
}

\author{
Adam D. Lietzan, Yi Lin and Martin St. Maurice*
}

Department of Biological Sciences, Marquette University, Milwaukee, WI 53201, USA

* To whom correspondence should be addressed: Marquette University, Department of Biological Sciences, PO Box 1881, Milwaukee, WI 53201 Ph: (414) 288-2087; fax: (414) 2887357; e-mail: martin.stmaurice@marquette.edu

Running Title: The carboxyltransferase reaction of pyruvate carboxylase

\section{Keywords}

Enzyme; Decarboxylation; Biotin; Oxaloacetate decarboxylase; Pyruvate carboxylase 


\begin{abstract}
Pyruvate carboxylase (PC) is a biotin-dependent enzyme that catalyzes the MgATP-dependent carboxylation of pyruvate to oxaloacetate, an important anaplerotic reaction in central metabolism. During catalysis, carboxybiotin is translocated to the carboxyltransferase domain where the carboxyl group is transferred to the acceptor substrate, pyruvate. Many studies on the carboxyltransferase domain of PC have demonstrated an enhanced oxaloacetate decarboxylation activity in the presence of oxamate and it has been shown that oxamate accepts a carboxyl group from carboxybiotin during oxaloacetate decarboxylation. The X-ray crystal structure of the carboxyltransferase domain from Rhizobium etli PC reveals that oxamate is positioned in the active site in an identical manner to the substrate, pyruvate, and kinetic data are consistent with the oxamate-stimulated decarboxylation of oxaloacetate proceeding through a simple ping-pong bi bi mechanism in the absence of the biotin carboxylase domain. Additionally, analysis of truncated PC enzymes indicates that the BCCP domain devoid of biotin does not contribute directly to the enzymatic reaction and conclusively demonstrates a biotin-independent oxaloacetate decarboxylation activity in PC. These findings advance the description of catalysis in PC and can be extended to the study of related biotin-dependent enzymes.
\end{abstract}


Pyruvate carboxylase (PC; EC 6.4.1.1) catalyzes the bicarbonate- and MgATP-dependent carboxylation of pyruvate to oxaloacetate. PC is an important anaplerotic enzyme and has been proposed to play a role in microbial virulence [1, 2], type-II diabetes [3-5], Alzheimer's disease [6], and cancer [7, 8]. In eukaryotes and most prokaryotes, the multifunctional PC enzyme exists as a homotetramer with each monomer being composed of four functional domains: the biotin carboxylase (BC) domain, the carboxyltransferase (CT) domain, the biotin carboxyl carrier protein $(\mathrm{BCCP})$ domain and the central allosteric domain (also termed the PC tetramerization, or PT, domain). In the first partial reaction, the N-terminal BC domain catalyzes the MgATP- and bicarbonate-dependent carboxylation of biotin. Carboxybiotin then physically translocates to the CT domain where the carboxyl moiety is transferred from biotin to pyruvate, thus forming oxaloacetate.

Kinetic isotope effect studies suggest that pyruvate carboxylation in the CT domain occurs in a stepwise manner (Scheme 1) $[9,10]$. Carboxybiotin, tethered to BCCP, enters the active site after pyruvate binds [11] and is decarboxylated to generate a biotin enolate intermediate [12]. A proton is subsequently shuttled from pyruvate to the biotin enolate via a conserved threonine residue, forming an enolpyruvate intermediate. Finally, the liberated $\mathrm{CO}_{2}$ is transferred to pyruvate, generating oxaloacetate [10].

The overall PC-catalyzed reaction thermodynamically favors the carboxylation of pyruvate. However, the enzyme can also catalyze the decarboxylation of oxaloacetate in the absence of other substrates. In this respect, PC also serves as a paradigm for two other biotin dependent enzymes that catalyze the decarboxylation of oxaloacetate: the oxaloacetate decarboxylase complex and transcarboxylase (reviewed in [13]). Thus, studies of oxaloacetate decarboxylation in PC are generally applicable to a range of biotin-dependent enzymes. 
The addition of oxamate has been shown to enhance the enzyme-catalyzed rate of oxaloacetate decarboxylation in PC $[14,15]$. This has enabled many isolated kinetic studies on the CT domain [10-12, 16]. Until recently, however, the mechanism by which oxamate accelerates the decarboxylation of oxaloacetate in PC was unknown. Marlier et al. partially resolved this issue by providing ${ }^{13} \mathrm{C}$ NMR evidence that oxamate serves as an alternate substrate in the CT domain reaction [17]. However, the initial velocity patterns were inconsistent with a simple ping-pong mechanism, leaving several aspects of the oxamate stimulation mechanism unresolved.

The description of oxaloacetate decarboxylation in PC is also plagued by contradictory literature reports concerning whether the biotin cofactor is essential for the decarboxylation reaction $[11,14,16,18,19]$. This is a crucial mechanistic question as it has significant implications on the stringency of the active site geometry and on the mode of carboxyl transfer. A major cause of these inconsistencies has been the variety of enzyme isolates and assay methods used to perform the studies.

Recent X-ray crystal structures of full-length PC [20, 21] have enabled new studies on the individual catalytic domains of the enzyme $[11,22]$. Such studies serve to complement those of the full-length enzyme by simplifying the overall system, contributing to a more complete description of the PC reaction mechanism. Here, we clarify both the oxamate-dependent and biotin-dependent oxaloacetate decarboxylation mechanisms of Rhizobium etli PC, using several truncated constructs to structurally and kinetically isolate the CT domain. We report that oxamate is positioned in the pyruvate binding site, consistent with oxamate serving as a carboxyl group acceptor in this reaction. Our kinetic data further suggest that, in the absence of a biotin carboxylase domain, the oxamate-stimulated decarboxylation of oxaloacetate proceeds through a 
simple ping-pong bi bi mechanism with double competitive substrate inhibition. Additionally, we present kinetic data in strong support of a biotin-independent decarboxylation of oxaloacetate and demonstrate that the BCCP domain requires a covalently attached biotin cofactor in order to accelerate the CT domain reaction.

\section{MATERIALS and METHODS}

General. IPTG, D-biotin, ampicillin, kanamycin, chloramphenicol, dithiothreitol (DTT), Tris buffer, epoxysuccinyl-L-leucylamido(4-guanido) butane (E-64), and pepstatin A were purchased from Research Products International Corp (Mount Prospect, IL). Lactate dehydrogenase was purchased from Roche Diagnostics (Indianapolis, IN). Acetyl-CoA was purchased from Crystal Chem, Inc (Downers Grove, IL). Granulated LB broth (Miller's modification) was purchased from EMD Millipore Chemicals, Inc. All other materials were purchased from Sigma-Aldrich. PC from Rhizobium etli (RePC) was previously subcloned into a modified pET-17b vector [20]. $\triangle \mathrm{BC} \operatorname{RePC}[23]$ and $\triangle \mathrm{BC} \Delta \mathrm{BCCP} \operatorname{RePC}[11]$ were previously subcloned into a modified pET-28a vector.

BCCP Domain Cloning and Site-Directed Mutagenesis. It was determined that Gly1069 represents the N-terminal end of the BCCP domain, based on the X-ray crystal structure of $\operatorname{RePC}$ (pdb i.d. 2QF7). However, when the BCCP domain from RePC is subcloned into the pET-28a expression vector with a $\mathrm{N}$-terminal (His) ${ }_{8}$ tag and expressed in E. coli, it does not effectively bind the $\mathrm{Ni}^{2+}$-NTA resin during purification. Therefore, the BCCP domain construct from $\operatorname{RePC}$ (ReBCCP) was N-terminally extended to begin at Gly1056. Construction of ReBCCP in the pET28a expression plasmid was as follows: $\sim 350 \mathrm{bp}$ fragment was PCR amplified from the wild-type RePC pET-17b template using the primers 5'-CCG CAT GCA TGG CCA GCC GCG CCG TAT 
C-3' (forward) and 5'-GCA GCG GCT AGC TCA TCC GCC GTA A-3' (reverse). The PCR amplified fragment was digested with NheI/NsiI and ligated into a PstI/NheI digested modified pET-28a-(His) ${ }_{8}$-TEV expression vector [23]. The K1119Q mutation was generated for the RePC, $\Delta \mathrm{BC} R e \mathrm{PC}$, and $\operatorname{Re} \mathrm{BCCP}$ constructs using the QuikChange site-directed mutagenesis protocol (Agilent Technologies; Santa Clara, CA) using primers designed to incorporate the mutation. Primers were synthesized by Integrated DNA Technologies (Coralville, IA) and the correct gene sequence of all PC constructs was confirmed by complete gene sequencing by Functional Biosciences, Inc. (Madison, WI).

Protein Expression and Purification. ReBCCP and the K1119Q mutant form of ReBCCP were expressed and purified in a similar manner. $R e$ BCCP in a pET-28a-(His) $)_{8}$ TEV plasmid was co-expressed in E. coli BL21Star(DE3) with E. coli biotin protein ligase A (BirA) on vector pCY216 [24]. The K1119Q form of ReBCCP was not co-expressed with BirA. Both K1119Q and wild-type ReBCCP were expressed in LB broth (Miller's modification) containing $50 \mathrm{mg} / \mathrm{L}$ kanamycin and $30 \mathrm{mg} / \mathrm{L}$ chloramphenicol (when co-expressing BirA). Cultures were grown at $37^{\circ} \mathrm{C}$ to an Optical Density $(600 \mathrm{~nm})$ of $0.4-0.5$, supplemented with D-biotin to a final concentration of $4 \mathrm{mg} / \mathrm{L}$, and induced with IPTG and L-arabinose to $1 \mathrm{mM}$ and $25 \mathrm{mM}$, respectively. Following induction, cultures were grown at $30^{\circ} \mathrm{C}$ for $17-19$ hours prior to harvesting.

The $R e B C C P$ proteins were purified to homogeneity using $\mathrm{Ni}^{2+}$-affinity and anion exchange chromatography. Harvested cells were re-suspended in a buffer containing $50 \mathrm{mM}$ Tris- $\mathrm{HCl}$ (pH 7.8), 5 mM imidazole, $200 \mathrm{mM} \mathrm{NaCl}, 0.5$ mM EGTA, 5 mM 2-mercaptoethanol, 1 $\mathrm{mM}$ phenylmethylsulfonyl fluoride (PMSF), $1 \mu \mathrm{M}$ pepstatin A, and $5 \mu \mathrm{M}$ E-64. Cells were disrupted by sonication on ice and the cell lysate was cleared by centrifugation at $10^{\circ} \mathrm{C}$ prior to 
loading onto a $10 \mathrm{~mL} \mathrm{Ni}^{2+}$-NTA Profinity resin column (Bio-Rad Life Sciences; Hercules, CA). The protein was eluted from the column in $50 \mathrm{mM}$ Tris- $\mathrm{HCl}(\mathrm{pH} 7.8), 200 \mathrm{mM} \mathrm{NaCl}, 0.5 \mathrm{mM}$ EGTA, $5 \mathrm{mM}$ 2-mercaptoethanol, with a gradient from $20 \mathrm{mM}$ to $250 \mathrm{mM}$ imidazole. Purified protein was pooled and incubated in $50 \mathrm{mM}$ Tris- $\mathrm{HCl}(\mathrm{pH} 7.8), 200 \mathrm{mM} \mathrm{NaCl}, 0.5 \mathrm{mM}$ EGTA, 5 mM 2-mercaptoethanol with His-tagged recombinant TEV (rTEV) protease at $4{ }^{\circ} \mathrm{C}(40: 1$ molar ratio of $R e \mathrm{BCCP}$ to $\mathrm{rTEV}$ protease). After (His) $)_{8}$ tag cleavage, the $\operatorname{Re} \mathrm{BCCP}$ sample was reapplied to a $\mathrm{Ni}^{2+}$-affinity column to remove the cleaved (His) $)_{8}$ tag and His-tagged-rTEV protease. Purified protein samples were pooled and dialyzed overnight in a buffer containing 20 $\mathrm{mM}$ triethanolamine ( $\mathrm{pH} \mathrm{8.0)}, 50 \mathrm{mM} \mathrm{NaCl}, 1 \mathrm{mM}$ EGTA, and $2 \mathrm{mM}$ DTT at $4^{\circ} \mathrm{C}$. Protein was flowed over a $10 \mathrm{~mL}$ column volume of Q-sepharose Fast Flow resin (GE Healthcare). Due to the high prevalence of positively charged residues at the N-terminal portion (theoretical $\mathrm{pI}$ for $\operatorname{Re} \mathrm{BCCP}$ is 8.33$), \operatorname{Re} \mathrm{BCCP}$ flows through the column while remaining impurities bind to the resin. The flow-through was pooled and dialyzed against a storage buffer consisting of $30 \mathrm{mM}$ Tris-HCl (pH 7.8), $50 \mathrm{mM} \mathrm{NaCl}$, and $2 \mathrm{mM}$ DTT. An Amicon stirred cell with a 3500 molecular weight cutoff filter was used to concentrate the $R e B C C P$ preparations to a range of $2-3 \mathrm{mg} / \mathrm{mL}$. Concentrated protein was flash frozen in liquid nitrogen and stored at $-80^{\circ} \mathrm{C}$. ReBCCP protein concentration was determined spectrophotometrically using the calculated molar extinction coefficient of $1490 \mathrm{M}^{-1} \mathrm{~cm}^{-1}$ at $280 \mathrm{~nm}$ [25].

Preparation and purification of the wild-type and mutant forms of $R e \mathrm{PC}, \Delta \mathrm{BC} R e \mathrm{PC}$ and $\triangle \mathrm{BC} \triangle \mathrm{BCCP} \operatorname{RePC}$ were performed as previously described [11, 23]. All forms of $\operatorname{Re} \mathrm{PC}$ and ReBCCP that do not contain the K1119Q mutation were $>95 \%$ biotinylated, as shown by SDSPAGE analysis of an avidin-gel shift assay (Figure S1) [12]. 
Kinetic assays for oxaloacetate decarboxylation in the presence and absence of oxamate.

The PC-catalyzed rate of oxaloacetate decarboxylation was determined by measuring the reduction of pyruvate to lactate using lactate dehydrogenase $[12,14]$. Reactions were performed in $0.1 \mathrm{M}$ Tris- $\mathrm{HCl}(\mathrm{pH} 7.8), 0.24 \mathrm{mM} \mathrm{NADH}$ and lactate dehydrogenase (10 U). Acetyl-CoA at $0.25 \mathrm{mM}$ was included for all reactions catalyzed by either wild-type or K1119Q RePC. Oxaloacetate was fixed at $1 \mathrm{mM}$ for all oxaloacetate decarboxylation reactions performed in the presence of $5 \mathrm{mM}$ biotin, $5 \mathrm{mM}$ biocytin or $1000 \times$ molar excess $R e \mathrm{BCCP}$ over the enzyme concentration. For reactions performed in the presence of oxamate, the oxaloacetate and oxamate concentrations were fixed at $0.2 \mathrm{mM}$ and $0.5 \mathrm{mM}$, respectively, unless specified. While $0.5 \mathrm{mM}$ oxamate is slightly inhibitory toward the coupling enzyme, the concentration of lactate dehydrogenase in the assay was sufficiently high so as to not be rate limiting in the coupled assay in the presence of $0.5 \mathrm{mM}$ oxamate (data not shown). In all cases, oxaloacetate was added prior to initiation of the reaction with enzyme $(400-900 \mu \mathrm{g})$. The half-life for the spontaneous decarboxylation of oxaloacetate is $2-6$ hours at room temperature [26]. Therefore, oxaloacetate solutions were prepared fresh, kept on ice for the duration of the kinetic experiments and added immediately prior to the initiation of the reaction. Additionally, non-enzymatic reactions were measured in parallel for every initial velocity measurement, allowing the enzyme independent rate of oxaloacetate decarboxylation to be subtracted from the enzyme-catalyzed rate. All reactions were conducted in a $1 \mathrm{~mL}$ reaction volume at $30^{\circ} \mathrm{C}$.

Data for the double reciprocal plot of velocity versus oxaloacetate concentrations for $\Delta \mathrm{BC} \operatorname{Re} \mathrm{PC}$ at fixed concentrations of oxamate were fit to the reciprocal of [eq 1] using leastsquares nonlinear regression, where $\mathrm{A}$ is the concentration of oxaloacetate, $\mathrm{B}$ is the concentration of oxamate, $K_{\mathrm{MA}}$ is the Michaelis constant for oxaloacetate, $K_{\mathrm{MB}}$ is the Michaelis constant for 
oxamate, $K_{i \mathrm{~A}}$ is the kinetic inhibition constant for oxaloacetate, and $K_{i \mathrm{~B}}$ is the kinetic inhibition constant for oxamate. This equation is derived from a ping-pong kinetic scheme with double competitive substrate inhibition, as outlined in scheme 2. Each data set was individually fit to the reciprocal of eq 1 using the least-squares error method with KaleidaGraph 4.1 software (Synergy Software, Reading, PA).

$$
v=\frac{V_{\max }[\mathrm{A}][\mathrm{B}]}{K_{\mathrm{MA}}[\mathrm{B}] 1+\frac{[\mathrm{B}]}{K_{i A}} \div+K_{\mathrm{MB}}[\mathrm{A}] 1+\frac{[\mathrm{A}]}{K_{i B}} \div+[\mathrm{A}][\mathrm{B}]}
$$

Pyruvate carboxylation assay for $\triangle B C \triangle B C C P$ RePC. Pyruvate carboxylation activity was determined spectrophotometrically by measuring the conversion of oxaloacetate to malate using malate dehydrogenase. Briefly, reaction assays were initiated by the addition of $\Delta \mathrm{BC} \Delta \mathrm{BCCP} \operatorname{Re} \mathrm{PC}(975 \mu \mathrm{g})$ or $\operatorname{RePC}$ wt $(350-700 \mu \mathrm{g})$ in a $1 \mathrm{~mL}$ reaction volume at $30^{\circ} \mathrm{C}$. Each reaction was performed in $50 \mathrm{mM} \mathrm{NaHCO}_{3}, 25 \mathrm{mM}$ pyruvate, $0.24 \mathrm{mM} \mathrm{NADH}$, and malate dehydrogenase $(30 \mathrm{U})$. Reactions were conducted in both $0.1 \mathrm{M}$ Tris- $\mathrm{HCl}(\mathrm{pH} 7.8)$ and $0.1 \mathrm{M}$ Tricine- $\mathrm{NaOH}(\mathrm{pH}$ 7.8) to evaluate the effects of various buffer systems on catalysis. For each velocity measurement, a non-enzymatic reaction rate was measured in parallel but no nonenzymatic rate was observed.

Protein Crystallization. $\triangle \mathrm{BC} \triangle \mathrm{BCCP} R e \mathrm{PC}$ was crystallized using the batch crystallization method under oil as previously described [11]. Crystallization conditions were similar for all crystals. For the $\triangle \mathrm{BC} \triangle \mathrm{BCCP} R e \mathrm{PC}$ structure containing pyruvate and biocytin, a protein solution consisting of $10 \mathrm{mg} / \mathrm{mL} \Delta \mathrm{BC} \Delta \mathrm{BCCP} R e \mathrm{PC}$ and $40 \mathrm{mM}$ pyruvate was mixed at a 1:1 ratio with a precipitant solution comprised of 11\%(w/v) PEG 8000, $100 \mathrm{mM}$ BisTris (pH 6.0 ), and $345 \mathrm{mM}$ tetramethylammonium chloride (TMACl). For the $\triangle \mathrm{BC} \triangle \mathrm{BCCP} \operatorname{RePC}$ 
structure containing oxamate and biotin, a protein solution consisting of $10 \mathrm{mg} / \mathrm{mL} \triangle \mathrm{BC} \triangle \mathrm{BCCP}$ $\operatorname{RePC}, 50 \mathrm{mM}$ oxamate, and $10 \mathrm{mM} 1^{\prime} \mathrm{N}$-acetyl-d-biotin [27] was mixed at a 1:1 ratio with a precipitant solution comprised of 14\% (w/v) PEG 8000, $110 \mathrm{mM}$ 3-morpholinopropane-1sulfonic acid (pH 6.0), $165 \mathrm{mM}$ TMACl, 2\% (v/v) glycerol, and $85 \mathrm{mM} \mathrm{1'N-acetyl-d-biotin.} \mathrm{A}$ seed stock was created using the seed bead kit from Hampton Research (Aliso Viejo, CA). Briefly, a single apoprotein $\triangle \mathrm{BC} \triangle \mathrm{BCCP} R e \mathrm{PC}$ crystal was pulverized in $500 \mu \mathrm{L}$ of precipitant solution and $0.5 \mu \mathrm{L}$ of this pulverized seed solution was added to the crystallization drop immediately following the mixing of the protein and precipitant solutions. The drop was covered with paraffin oil and octahedral crystals formed within 2-3 days. After 5-7 days, the crystals were harvested. Crystals of $\triangle \mathrm{BC} \triangle \mathrm{BCCP} R e \mathrm{PC}$ co-crystallized with pyruvate were transferred and soaked in a synthetic mother liquor solution containing 10\% (w/v) PEG 8000, $80 \mathrm{mM}$ BisTris (pH 6.0), $200 \mathrm{mM} \mathrm{TMACl}, 20 \mathrm{mM}$ pyruvate and $80 \mathrm{mM}$ biocytin for 20 hours at room temperature. Crystals were then serially transferred in $5 \%(\mathrm{v} / \mathrm{v})$ glycerol increments from the synthetic mother liquor solution to a cryoprotectant solution consisting of $11 \%(w / v)$ PEG 8000 , $90 \mathrm{mM}$ BisTris (pH 6.0), $200 \mathrm{mM}$ TMACl, $20 \mathrm{mM}$ pyruvate, $80 \mathrm{mM}$ biocytin, and 20\% (v/v) glycerol and flash cooled in liquid nitrogen. Crystals of $\triangle \mathrm{BC} \triangle \mathrm{BCCP} R e \mathrm{PC}$ co-crystallized with oxamate and biotin were transferred in an identical manner, excepting that $50 \mathrm{mM}$ oxamate and $50 \mathrm{mM}$ 1'N-acetyl-d-biotin replaced the $80 \mathrm{mM}$ biocytin and $20 \mathrm{mM}$ pyruvate. The cryoprotected crystals were immediately flash cooled in liquid nitrogen.

Data collection, structure determination, and refinement. X-ray diffraction data were collected at the Advanced Photon Source (APS, Argonne, IL), beamline LS-CAT 21-ID-D and 21-ID-F on Rayonix MarMosaic 300 CCD and 225 CCD detectors, respectively. The wavelength was tuned to $1.127 \AA$ for the structure with pyruvate and biocytin (collected on 21-ID-D) and 
$0.979 \AA$ for the structure with oxamate and biotin (collected on 21-ID-F). Diffraction images were processed with the HKL2000 suite [28]. The structures were solved by molecular replacement using the structure of $\triangle \mathrm{BC} \triangle \mathrm{BCCP} R e \mathrm{PC}$ (pdb i.d. 4JX4) as the search model with the program Phaser [29]. Following molecular replacement, translation/libration/screw (TLS) refinements were performed using REFMAC [30-32]. Each monomer was treated as a rigid TLS group. All four monomers in the asymmetric unit were restrained using non-crystallographic symmetry for all models during the entire refinement process. The models were extended by several rounds of manual model building with COOT [33] and successive refinements with REFMAC. Water molecules were added to the models in COOT with subsequent manual verification. Data collection and processing statistics are summarized in Table 1.

\section{RESULTS}

Effects of biotin, biocytin and BCCP on oxaloacetate decarboxylation. The role of biotin in the biotin-dependent carboxylases has largely been studied for the biotin carboxylation reaction of the $\mathrm{BC}$ domain [34-38]. The role of biotin in the carboxyl transfer reactions of various biotin-dependent carboxylases, however, has not been extensively characterized outside of the carboxyltransferase subunit of Escherichia coli acetyl-CoA carboxylase [39-41]. Structural studies of $S$. aureus PC reveal that the BCCP domain physically interacts with the CT domain in order to facilitate biotin binding in the CT domain active site [21, 42], but it is not known whether the BCCP-CT domain interaction is required in order for biotin to participate in the carboxyltransferase reaction. To better study the contribution of BCCP-biotin and its individual components to the carboxytransferase activity in PC, structure-guided truncations of the $\operatorname{RePC}$ holoenzyme were generated to enable a thorough investigation of the role of biotin in 
the CT domain reaction (Figure 1). The rate of oxaloacetate decarboxylation was measured in the presence of free biotin, biocytin and ReBCCP-biotin for various truncated and full-length constructs of $\operatorname{RePC}$.

All of the $R e \mathrm{PC}$ constructs examined in the present study maintain an intrinsic rate of oxaloacetate decarboxylation, irrespective of whether or not the enzyme is biotinylated (Table 2). At $1 \mathrm{mM}$ oxaloacetate, wt $\operatorname{RePC}$ catalyzes the decarboxylation of oxaloacetate to pyruvate $\sim 2$ fold faster than $\triangle \mathrm{BC} R e \mathrm{PC}$ or $\triangle \mathrm{BC} \Delta \mathrm{BCCP} R e \mathrm{PC}$. Mutating Lys1119, the site of biotinylation in $R e \mathrm{PC}$, slightly reduces oxaloacetate decarboxylation compared to the biotinylated forms but the same trend holds, with the full length K1119Q RePC catalyzing oxaloacetate decarboxylation 2-fold faster than the $\Delta \mathrm{BC} \mathrm{K} 1119 \mathrm{Q} R e \mathrm{PC}$. For each of the constructs examined in the present study, the addition of $5 \mathrm{mM}$ free biotin or biocytin enhances the rate 2-fold and 4-fold, respectively, over the intrinsic rate of oxaloacetate decarboxylation. Addition of a 1000 -fold molar excess of biotinylated-ReBCCP greatly enhances the rate of oxaloacetate decarboxylation, up to 110 -fold in the case of $\triangle \mathrm{BC} \triangle \mathrm{BCCP} \operatorname{RePC}$. None of the $\operatorname{Re} \mathrm{PC}$ variants exhibit a rate enhancement for oxaloacetate decarboxylation in the presence of the non-biotinylated K1119Q ReBCCP (Figure S2). Further, addition of biocytin to the reaction mixture containing nonbiotinylated K1119Q ReBCCP does not enhance the rate of oxaloacetate decarboxyation (Figure S2). Finally, when an essential arginine residue (Arg621) responsible for binding pyruvate/oxaloacetate in the $\mathrm{CT}$ domain active site is mutated (R621A $\triangle \mathrm{BC} \triangle \mathrm{BCCP}$ ), the enzyme-catalyzed biotin-independent oxaloacetate decarboxylation activity is completely eliminated (Table S1), demonstrating that the enzyme activity is specific and originates in the CT domain active site. 
Given that $\triangle \mathrm{BC} \triangle \mathrm{BCCP} R e \mathrm{PC}$ decarboxylates oxaloacetate in the absence of biotin, it is expected that this construct can also catalyze the carboxylation of pyruvate. The pyruvate carboxylation activities for $\triangle \mathrm{BC} \triangle \mathrm{BCCP} R e \mathrm{PC}$ were unaffected by changes in buffer composition (Table S1), indicating that this is not a buffer-catalyzed reaction. Pyruvate carboxylation was not observed when either the enzyme or pyruvate was omitted from the reaction mixture, demonstrating that the observed rates, while slow, are enzyme-catalyzed. The MgATPindependent pyruvate carboxylation activity for wt $R e \mathrm{PC}$ was determined to be $0.044 \pm 0.001$ $\min ^{-1}$.

Effects of oxamate on the oxaloacetate decarboxylation reaction. Oxamate stimulates the PC-catalyzed rate of oxaloacetate decarboxylation[14]. Recently, Marlier et al [17] provided ${ }^{13} \mathrm{C}-$ NMR evidence demonstrating that oxamate accepts the carboxyl group from oxaloacetate and proposed that biotin facilitates the carboxyl group transfer between these substrates. However, the steady-state kinetics were inconsistent with a simple ping-pong mechanism, suggesting that biotin decarboxylation was occurring through two competing pathways at low concentrations of oxamate. To clearly determine whether oxamate binds in the $\mathrm{CT}$ domain active site, $\triangle \mathrm{BC} \triangle \mathrm{BCCP}$ $R e \mathrm{PC}$ was co-crystallized with oxamate. The structure reveals that the binding orientation for oxamate is identical to that observed for pyruvate (Figure 2). The carboxyl group of oxamate forms a salt bridge interaction with the guanidinium group of Arg621 while the carbonyl oxygen is within hydrogen bonding distance of the side chains of Arg548 and Gln552. The binding of oxamate in the active site promotes the interaction between Tyr628 and Asp590, which forms a biotin binding pocket in the active site [11].

To further investigate the reaction pathway for the oxamate-stimulated decarboxylation of oxaloacetate, the oxamate independent and dependent rates of oxaloacetate decarboxylation 
were measured for various engineered constructs of $\operatorname{RePC}$ (Table 3). As observed previously [17], the wild-type rate of oxaloacetate decarboxylation is enhanced 3-fold in the presence of $0.5 \mathrm{mM}$ oxamate. A mutation at the site of biotinylation in $R e P C, K 1119 Q$, eliminates the oxamatedependent rate enhancement for oxaloacetate decarboxylation. When the $\mathrm{BC}$ domain is truncated from the enzyme ( $\triangle \mathrm{BC} R e \mathrm{PC})$, the decarboxylation of oxaloacetate is enhanced 20 -fold in the presence of oxamate and there is no rate enhancement in the K1119Q mutation of $\Delta \mathrm{BC} \operatorname{RePC}$. Truncating both the $\mathrm{BC}$ and $\mathrm{BCCP}$ domains also eliminates the oxamate-induced rate enhancement. These results are consistent with the proposal that oxamate binds in the CT domain and serves to accept the carboxyl group from carboxybiotin.

Double reciprocal plots obtained at varying oxaloacetate concentrations and fixed concentrations of oxamate are consistent with a simple Ping Pong Bi Bi kinetic mechanism that is subject to double competitive substrate inhibition (Figure 3). Such a pattern is expected when both substrates form a dead-end complex with an inappropriate enzyme form [44].

Biotin and biocytin binding in $\triangle B C \triangle B C C P$ RePC. The $\triangle \mathrm{BC} \triangle \mathrm{BCCP} R e \mathrm{PC}$ was cocrystallized in the presence of pyruvate or oxamate and soaked with free 1 ' $\mathrm{N}$-acetyl-d-biotin or biocytin prior to data collection. As previously reported, $\triangle \mathrm{BC} \Delta \mathrm{BCCP} R e \mathrm{PC}$ crystallizes in the space group $P 2{ }_{1} 2_{1} 2_{1}$ with the four monomers of the asymmetric unit arranging as a tetramer [45]. Electron density corresponding to free biotin or biocytin was not observed in the active site of the CT domain. Instead, in both structures, biotin or biocytin were both observed bound in the well characterized biotin exo-binding site, at the interface between the central spanning $\alpha$-helix of the allosteric domain and the CT domain (Figure S3) [21,46]. There is no evidence for acetylation at the 1 ' $N$ position of biotin in the electron density (Figure S3), suggesting that the acetyl group was hydrolyzed. Consequently, the ligand in the exo binding site corresponds to the 
unmodified biotin. The observed electron density for the ureido ring of free biotin and biocytin is clearly defined in all four exo-binding sites of the asymmetric unit, with monomer A exhibiting the lowest temperature factors for both ligands.

Electron density corresponding to biocytin is also observed in the funnel leading to the active site of the CT domain (Figure 4; Figure S4). However, the N-1 of biocytin is displaced $15.9 \AA$ away from the active site metal, $\sim 7 \AA$ from the biotin binding position observed in the active site of the Homo sapiens PC (pdb i.d. 3BG3) and S. aureus PC crystal structures (pdb i.d. 3BG5). Biocytin maintains contacts in a ridge leading to the entrance of the active site with its most significant interactions occurring with $\alpha$-helix 10 (Gly842 - Leu857) of the CT domain. Notably, the position of $\alpha$-helix 10 has been shown to be perturbed when BCCP binds with the CT domain of PC [21].

\section{DISCUSSION}

Contribution of the BCCP domain to the biotin-catalyzed carboxyl transfer reaction of $P C$. All of the PC variants examined in the present study exhibited a clear rate enhancement for oxaloacetate decarboxylation in the presence of free biotin, biocytin and BCCP-biotin. A similar biotin-dependent rate enhancement has been reported for Bacillus thermodenitrificans PC [18]. The rate enhancement is dependent on the degree to which the biotin side-chain mimics the biotinylated enzyme. Biotin, which has a valeric acid substituent extending from the tetrahydrothiophene ring, is least effective at enhancing the rate. From the crystal structures of BCCP-biotin bound in the $\mathrm{CT}$ domain active site of Homo sapiens PC (HsPC; pdb i.d. 3BG3) and Staphylococcus aureus PC (SaPC; pdb i.d. 3BG5) [21], it is likely that the positioning of free biotin is impeded by a charge repulsion between the side chain of Asp590 (conserved in all PC 
enzymes) and the valeric acid carboxylate of biotin, making free biotin a less effective substrate compared to biocytin and ReBCCP-biotin. A similar trend has been observed in the E. coli carboxyltransferase subunit of acetyl-CoA carboxylase, where biocytin affords a $V_{\max }$ increase that is three orders of magnitude greater than biotin[41]. In an apparently contradictory result, Adina-Zada et al reported that free biotin did not enhance the rate of oxaloacetate decarboxylation in the K1112A mutant of Bacillus thermodenitrificans PC (equivalent to the K1119Q mutant in $R e P C)$ [19]. However, in those studies, oxaloacetate decarboxylation was assayed in the presence of oxamate, which requires a tethered biotin cofactor for activity (see below).

The rate of oxaloacetate decarboxylation is enhanced 60- to 110 -fold in the presence of the bona fide substrate, BCCP-biotin. In an earlier study, BCCP-biotin was also reported to be more effective than free biotin in enhancing the rate of oxaloacetate decarboxylation in PC from Bacillus thermodenitrificans[18]. Similarly, in E. coli carboxyltransferase, a 2000-fold increase over biotin was observed when the biotinylated C-terminal BCCP domain was used as a substrate in place of free biotin [41]. The most likely interpretation of these data is that the BCCP-CT domain interaction contributes to the proper positioning of biotin in the active site. However, the crystal structures of $H_{s} \mathrm{PC}$ (pdb i.d. 3BG3) and $S a \mathrm{PC}$ (pdb i.d. 3BG5) reveal a rotation in $\alpha$-helix 10 of the $\mathrm{CT}$ domain that accompanies the BCCP-CT domain interaction [21]. The $\alpha$-helix 10 extends into the CT active site, raising the possibility that the BCCP-CT domain interaction directly influences catalysis in the CT domain through alterations in this $\alpha$-helix. In the present study, the K1119Q BCCP domain, which lacks a tethered biotin, is unable to enhance oxaloacetate decarboxylation and addition of free biocytin in the presence of the K1119Q BCCP domain does not rescue this activity. Together, these results indicate that the BCCP-CT domain 
interaction does not directly enhance catalysis and serves only to properly position the carboxybiotin cofactor in the active site.

It is noteworthy that removing the $\mathrm{BC}$ domain from $\operatorname{Re} \mathrm{PC}$ reduces the rate of oxaloacetate decarboxylation to $40 \%$ that of full length $\mathrm{RePC}$, irrespective of whether the enzyme is biotinylated (Table 1 ). In solution, $R e \mathrm{PC}$ is a tetramer while $\Delta \mathrm{BC} R e \mathrm{PC}$ is a dimer [23]. The reduced activity observed in RePC enzymes lacking a BC domain indicates that either the $\mathrm{BC}$ domain itself or enzyme tetramerization influences the biotin-independent $\mathrm{CT}$ domain activity. The $\mathrm{BC}$ domain homodimer from E. coli acetyl-CoA carboxylase has been shown to exhibit synergism amongst the dimer active sites [47]. The current study, however, offers direct evidence for communication between the $\mathrm{BC}$ and $\mathrm{CT}$ domains in $\mathrm{PC}$, even in the absence of a biotin cofactor. Parallel studies have revealed that the CT domain can influence the BC domain activity [12], indicating that an as yet undetermined communication network is likely to exist between the individual catalytic domains of PC.

Oxamate induced oxaloacetate decarboxylation proceeds through a Ping-Pong Bi Bi kinetic mechanism. Oxamate stimulates the rate of oxaloacetate decarboxylation in PC enzymes isolated from chicken liver and $R e P C$. Recently, it was demonstrated that $\mathrm{CO}_{2}$ is transferred from oxaloacetate to oxamate, with biotin most likely serving as a conduit [17]. However, the reported initial velocity kinetics displayed sigmoidicity, suggesting an alternate route of decarboxylation for carboxybiotin and leaving some aspects of the mechanism unresolved.

This study offers several new lines of evidence in support of a ping-pong mechanism for the oxamate-induced oxaloacetate decarboxylation reaction in the CT domain. The structure of RePC co-crystallized with oxamate clearly shows oxamate bound in the pyruvate binding site (Figure 2), and the active site is observed in the closed conformation that is correlated with 
ligand binding in the CT domain active site [11]. The structure, therefore, is consistent with oxamate serving as the terminal carboxyl group acceptor in a ping pong-like reaction mechanism [17]. Furthermore, the $\mathrm{RePC}$ constructs in the current study display kinetic features that are fully consistent with a biotin-dependent $\mathrm{CO}_{2}$ transfer from oxaloacetate to oxamate: in all constructs where the site of biotinylation is mutated $(\mathrm{K} 1119 \mathrm{Q})$ or the BCCP domain is absent, oxamate no longer accelerates the rate of oxaloacetate decarboxylation. Additionally, in the presence of a tethered biotin cofactor, the steady-state kinetics are fully consistent with a ping-pong mechanism with double competitive substrate inhibition, indicating that both pyruvate and oxamate share the same binding site (Figure 3).

Marlier et al observed that, in wild-type RePC, carboxybiotin can decarboxylate through an alternate pathway [17]. In the current study, oxamate induced decarboxylation kinetics were measured in $\triangle \mathrm{BC} R e \mathrm{PC}$, where decarboxylation in the $\mathrm{BC}$ domain is not a possibility. The double reciprocal plot of velocity against oxaloacetate concentration for $\Delta \mathrm{BC} R e \mathrm{PC}$, at fixed concentrations of oxamate, show a pattern that is consistent with a simple ping pong bi bi mechanism with double competitive substrate inhibition (Figure 3). Unlike with wild-type RePC, no sigmoidicity is observed in the velocity vs. [S] plots of $\Delta \mathrm{BC} R e \mathrm{PC}$, indicating that no alternate pathway for carboxybiotin decarboxylation is present in $\Delta \mathrm{BC} R e \mathrm{PC}$. Thus, the most likely alternative route for decarboxylation of carboxybiotin in wild-type PC is through enzymemediated decarboxylation in the $\mathrm{BC}$ domain active site [48]. Following $\mathrm{CO}_{2}$ transfer from oxaloacetate to biotin in the wild-type enzyme, carboxybiotin has two possible fates (Scheme 2): (1) Pyruvate exits the active site, allowing oxamate to bind and accept $\mathrm{CO}_{2}$ from carboxybiotin or (2) carboxybiotin translocates to the $\mathrm{BC}$ domain where it decarboxylates without forming the carbamylated oxamate. This second pathway for carboxybiotin decarboxylation explains the 
sigmoidicity observed by Marlier et al in the wild-type RePC kinetics [17] and provides evidence that carboxybiotin can access and decarboxylate in the $\mathrm{BC}$ domain of the wild-type enzyme, even in the absence of $\mathrm{BC}$ domain substrates.

A biotin-independent mechanism for oxaloacetate decarboxylation. This study clearly and unambiguously demonstrates that biotin is not required for oxaloacetate decarboxylation by PC. All of the engineered RePC variants that lack a tethered biotin (K1119Q RePC, K1119Q $\Delta \mathrm{BC} R e \mathrm{PC}$ and $\triangle \mathrm{BC} \triangle \mathrm{BCCP} R e \mathrm{PC}$ ) retained oxaloacetate decarboxylation activity (Table 2).

To this point, there have been mixed reports regarding the absolute requirement for biotin on the oxaloacetate decarboxylation reaction in PC. A biotin-independent oxaloacetate decarboxylation activity was first described for chicken liver PC following incubation with avidin [49]. This finding was corroborated by the report of a concentration dependent biotinindependent rate of oxaloacetate decarboxylation for chicken liver PC incubated with avidin [14] and has also been observed in B. thermodenitrificans PC in the absence of a BCCP domain[18]. However, mutations at the biotinylation site in both B. thermodenitrificans $\mathrm{PC}$ and $\operatorname{Re} \mathrm{PC}$ completely eliminated the oxamate-induced oxaloacetate decarboxylation activity, leading to the contradictory claim that biotin is required for oxaloacetate decarboxylation in PC [12, 19]. To address this discrepancy, we measured the oxamate independent rate of oxaloacetate decarboxylation by $\mathrm{RePC}$ under assay conditions identical to those previously reported [19] (Figure S5). Our results unequivocally show a biotin-independent oxaloacetate decarboxylation activity for the $\mathrm{K} 1119 \mathrm{Q}$ and $\triangle \mathrm{BC} \triangle \mathrm{BCCP} \operatorname{RePC}$ mutant in the absence of oxamate. The oxaloacetate decarboxylation activity of $\triangle \mathrm{BC} \triangle \mathrm{BCCP} R e \mathrm{PC}$ is completely eliminated by the R621A mutation, demonstrating that the activity is enzyme-catalyzed (Table S1). 
We attribute the inconsistent reports of biotin-independent oxaloacetate decarboxylation in PC to the inclusion of oxamate in certain studies. While oxamate accelerates the biotindependent rate of oxaloacetate decarboxylation by serving as the carboxyl group acceptor from carboxybiotin, it does not participate in the biotin independent oxaloacetate decarboxylation. The present study reveals that oxamate occupies an identical binding site as pyruvate (Figure 2) and, at high concentrations, competes with oxaloacetate (Figure 3). Therefore, the addition of oxamate to biotin-deficient mutants (e.g. K1119Q) competes with oxaloacetate for the enzyme active site and reduces the reaction rate, leading investigators to report that PC is unable to catalyze oxaloacetate decarboxylation in the absence of biotin.

The biotin-independent oxaloacetate decarboxylation is expected to proceed via a similar mechanism to that proposed for the biotin-dependent decarboxylation reaction, where a concerted proton transfer between oxaloacetate and biotin facilitates carboxyl transfer [12]. When biotin is not present, another substrate must serve as the proton donor and, subsequently, serve as the nucleophile to attack the liberated $\mathrm{CO}_{2}$. Two possible candidates may serve as proton donors in the absence of biotin: the reaction buffer or water. Given that the biotinindependent reaction proceeds in a variety of distinct buffer systems [14, 16, 49], the more likely proton donor is water (Scheme 3). The crystal structure of $\triangle \mathrm{BC} \Delta \mathrm{BCCP} R e \mathrm{PC}$ with pyruvate (pdb i.d. 4JX5) contains several ordered water molecules in the active site (Figure S6). Of particular interest is a water molecule occupying a site $2.9 \AA$ from Thr882, at a location near to that occupied by the N-1 of tethered biotin in the crystal structure of $H_{s} \mathrm{PC}$ and $\mathrm{SaPC}$ [21]. Similar to the ureido oxygen of biotin, this water molecule forms a hydrogen-bonding network with the

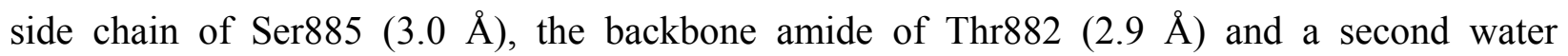
molecule (2.5 $\AA)$. The $\mathrm{p} K_{a}$ of water (15.7) is similar to the $\mathrm{p} K_{a}$ for the N-1 of biotin $(\sim 17 ;[50])$, 
making it an equivalent proton donor, provided that the hydrogen-bonding network in the active site can stabilize the hydroxide ion in a similar manner to the biotin enolate. The stabilized hydroxide will subsequently react with the liberated $\mathrm{CO}_{2}$ to form bicarbonate, completing the reaction cycle. A similar biotin-independent mechanism has been proposed for the nonhomologous oxaloacetate decarboxylase PA4872 from Pseudomonas putida, where a water molecule is thought to serve as the acid that donates a proton to the pyruvate enolate [51].

The biotin-independent mechanism in scheme 3 predicts that the isolated CT domain ( $\triangle \mathrm{BC} \triangle \mathrm{BCCP} R e \mathrm{PC}$ ) will catalyze the formation of oxaloacetate from pyruvate and bicarbonate. Indeed, $\triangle \mathrm{BC} \triangle \mathrm{BCCP} R e \mathrm{PC}$ catalyzes pyruvate carboxylation at a reduced rate $\left(\mathrm{k}_{\mathrm{cat}} \sim 0.1 \mathrm{~min}^{-1}\right)$ in the absence of biotin and in the presence of bicarbonate and pyruvate. While this is 3-4 orders of magnitude slower than the pyruvate carboxylation reaction catalyzed by wt $R e \mathrm{PC}$ in the presence of ATP and $\mathrm{HCO}_{3}{ }^{-}$, the activity is consistent with water serving as a proton donor in the biotinindependent oxaloacetate decarboxylation reaction and reveals that the CT domain active site of PC can independently fix $\mathrm{CO}_{2}$, albeit at a very slow rate.

Exogenous biotin binding sites in PC. Both free biotin and biocytin enhance the rate of oxaloacetate decarboxylation in the $\mathrm{CT}$ domain of $\mathrm{RePC}$, with biocytin enhancing the rate 2-fold compared to biotin. To better describe the origin of these rate enhancements, $\triangle \mathrm{BC} \triangle \mathrm{BCCP} R e \mathrm{PC}$ was co-crystallized with either pyruvate or oxamate and soaked with either free biotin or biocytin prior to data collection. While biotin and biocytin were not observed in the active site, these structures revealed that exogenous biotin binds to the enzyme at specific subsites.

Electron density corresponding to both biotin and biocytin was observed in the exobinding site. Several prior structures have revealed that the biotin cofactor, when tethered to the BCCP domain, binds at this exo site at the interface of the allosteric and CT domains $[21,46]$. 
While the function of the exo-binding site is unknown, an intriguing hypothesis is that this site, which appears to be unique to bacterial PC enzymes [21], serves to increase the local concentration of free biotin. The binding of free biotin in the exo-binding site may promote the biotinylation of the BCCP domain by biotin protein ligase, affording a degree of posttranslational control to the enzyme.

Electron density corresponding to biocytin was also observed in the funnel leading into the CT domain active site (Figure 4). The funnel exhibits a largely positive surface charge distribution. While we cannot rule out that this additional binding position is simply an artifact of crystallization, the apparent affinity of the cofactor for this site suggests that the funnel may assist in directing the negatively charged carboxybiotin into the active site. Therefore, this structure may represent a snapshot of the path traversed by carboxybiotin as it gains access to the active site.

It is clear from this study that the rate enhancement observed for the biotin-dependent decarboxylation of oxaloacetate results from oxamate serving as a carboxyl group acceptor and that, in the absence of biotin and oxamate, the $\mathrm{CT}$ domain retains oxaloacetate decarboxylation activity. This establishes oxaloacetate decarboxylation assays in the presence and absence of oxamate as an effective means to dissect the role of biotin in the PC-catalyzed reaction. Such assays have already been applied to investigate specific residues in substrate binding and enolate stabilization in the $\mathrm{CT}$ domain reaction of $\mathrm{PC}[11]$. It is anticipated that investigations of the homologous biotin-dependent enzymes, transcarboxylase and the oxaloacetate decarboxylase complex, will also substantially benefit from the application of these assays. Interestingly, the rate of oxaloacetate decarboxylation in the isolated $\alpha$-subunit of the oxaloacetate decarboxylase complex is approximately 20 -fold higher than it is in the equivalent $\Delta \mathrm{BC}$ construct of $\operatorname{RePC}[52]$. 
This suggests that, while all three homologous biotin-dependent enzymes are structured to stabilize the pyruvate and biotin enolate intermediates, the oxaloacetate decarboxylase complex is predisposed to catalyze the decarboxylation reaction. A description of the molecular basis for these distinct differences between homologous enzymes awaits further structural and kinetic studies.

\begin{abstract}
ABBREVIATIONS
APS, Advanced Photon Source; BC, biotin carboxylase; BCCP, biotin carboxyl carrier protein; BirA, biotin protein ligase; BisTris, 2-[Bis(2-hydroxyethyl)amino]-2-(hydroxymethyl)propane1,3-diol; CT, carboxyltransferase; DTT, dithiothreitol; E-64, epoxysuccinyl-L-leucylamido(4guanido) butane; HsPC, Homo sapiens pyruvate carboxylase; IPTG, isopropyl $\beta$-D-1thiogalactopyranoside; LS-CAT, Life Sciences Collaborative Access Team; PC, pyruvate carboxylase; PEG, poly(ethylene glycol); PMSF, phenylmethanesulfonyl fluoride; ReBCCP, Rhizobium etli biotin carboxyl carrier protein; RePC, Rhizobium etli pyruvate carboxylase; rTEV protease, recombinant tobacco etch virus protease; SaPC, Staphylococcus aureus pyruvate carboxylase; SDS-PAGE, sodium dodecyl sulfate-polyacrylamide gel electrophoresis; TMACl, tetramethylammonium chloride
\end{abstract}

\title{
ACKNOWLEDGEMENTS
}

This work was supported by the National Institute of Health grant GM070455 to W.W. Cleland, John C. Wallace, Paul V. Attwood and Martin St. Maurice and National Science Foundation MRI-R2 grant DBI-0959442 to Martin St. Maurice. Adam D. Lietzan is supported by a Schmitt fellowship from the Arthur J. Schmitt Foundation. Use of the Advanced Photon Source was supported by U.S. Department of Energy, Office of Science, Office of Basic Energy Sciences, under contract No. DE-AC02-06CH11357. Use of the LS-CAT Sector 21 was supported by the Michigan Economic Development Corporation and the Michigan Technology Tri-Corridor for the support of this research program (Grant 085P1000817).

\section{SUPPORTING INFORMATION}


Supporting supplementary material includes Table S1 and Figures S1-S6.

\section{ACCESSION CODES}

The atomic coordinates for $(\triangle \mathrm{BC} \triangle \mathrm{BCCP} R e \mathrm{PC}+$ pyruvate + biocytin $)$ and $(\triangle \mathrm{BC} \Delta \mathrm{BCCP} \operatorname{Re} \mathrm{PC}+$ oxamate + biotin) have been deposited in the Protein Data Bank as entry 4M6V and 4LOC, respectively.

\section{REFERENCES}

[1] J. Schar, R. Stoll, K. Schauer, D.I. Loeffler, E. Eylert, B. Joseph, W. Eisenreich, T.M. Fuchs, W. Goebel, J. Bacteriol. 192 (2010) 1774-1784.

[2] I. Kukavica-Ibrulj, F. Sanschagrin, A. Peterson, M. Whiteley, B. Boyle, J. Mackay, R.C. Levesque, Microbiology 154 (2008) 2106-2118.

[3] J. Han and Y.Q. Liu, J. Endocrinol. 204 (2010) 143-152.

[4] M.J. MacDonald, M.J. Longacre, E.C. Langberg, A. Tibell, M.A. Kendrick, T. Fukao, C.G. Ostenson, Diabetologia 52 (2009) 1087-1091.

[5] N.M. Hasan, M.J. Longacre, S.W. Stoker, T. Boonsaen, S. Jitrapakdee, M.A. Kendrick, J.C. Wallace, M.J. MacDonald, J. Biol. Chem. 283 (2008) 28048-28059.

[6] V. Tiwari and A.B. Patel, J. Alzheimers Dis. (2014)

[7] T.W. Fan, A.N. Lane, R.M. Higashi, M.A. Farag, H. Gao, M. Bousamra, D.M. Miller, Mol. Cancer. 8 (2009) 41.

[8] T. Cheng, J. Sudderth, C. Yang, A.R. Mullen, E.S. Jin, J.M. Mates, R.J. DeBerardinis, Proc. Natl. Acad. Sci. U. S. A. 108 (2011) 8674-8679.

[9] S.J. O'Keefe and J.R. Knowles, Biochemistry 25 (1986) 6077-6084.

[10] P.V. Attwood, P.A. Tipton, W.W. Cleland, Biochemistry 25 (1986) 8197-8205.

[11] A.D. Lietzan and M. St Maurice, J. Biol. Chem. 288 (2013) 19915-19925.

[12] T.N. Zeczycki, M. St Maurice, S. Jitrapakdee, J.C. Wallace, P.V. Attwood, W.W. Cleland, Biochemistry 48 (2009) 4305-4313.

[13] A.D. Lietzan and M. St. Maurice, Arch. Biochem. Biophys. 544 (2014) 75-86.

[14] P.V. Attwood and W.W. Cleland, Biochemistry 25 (1986) 8191-8196.

[15] G.J. Goodall, G.S. Baldwin, J.C. Wallace, D.B. Keech, Biochem. J. 199 (1981) 603-609.

[16] S. Duangpan, S. Jitrapakdee, A. Adina-Zada, L. Byrne, T.N. Zeczycki, M. St Maurice, W.W. Cleland, J.C. Wallace, P.V. Attwood, Biochemistry 49 (2010) 3296-3304.

[17] J.F. Marlier, W.W. Cleland, T.N. Zeczycki, Biochemistry 52 (2013) 2888-2894.

[18] M.N. Islam, S. Sueda, H. Kondo, Protein Eng. Des. Sel. 18 (2005) 71-78.

[19] A. Adina-Zada, S. Jitrapakdee, K.H. Surinya, M.J. McIldowie, M.J. Piggott, W.W. Cleland, J.C. Wallace, P.V. Attwood, Int. J. Biochem. Cell Biol. 40 (2008) 1743-1752.

[20] M. St Maurice, L. Reinhardt, K.H. Surinya, P.V. Attwood, J.C. Wallace, W.W. Cleland, I. Rayment, Science 317 (2007) 1076-1079. 
[21] S. Xiang and L. Tong, Nat. Struct. Mol. Biol. 15 (2008) 295-302.

[22] A.D. Lietzan and M. St Maurice, Biochem. Biophys. Res. Commun. 441 (2013) 377-382.

[23] A.D. Lietzan, A.L. Menefee, T.N. Zeczycki, S. Kumar, P.V. Attwood, J.C. Wallace, W.W.

Cleland, M. St Maurice, Biochemistry 50 (2011) 9708-9723.

[24] A. Chapman-Smith, D.L. Turner, J.E. Cronan Jr, T.W. Morris, J.C. Wallace, Biochem. J.

302 ( Pt 3) (1994) 881-887.

[25] E. Gasteiger, C. Hoogland, A. Gattiker, S. Duvaud, M.R. Wilkins, R.D. Appel, A. Bairoch, in: J.M. Walker (Ed.), The Proteomics Protocols Handbook, Humana Press, 2005, pp. 571-607.

[26] R. Wolfenden, C.A. Lewis Jr, Y. Yuan, J. Am. Chem. Soc. 133 (2011) 5683-5685.

[27] S.E. Polakis, R.B. Guchhait, E.E. Zwergel, M.D. Lane, T.G. Cooper, J. Biol. Chem. 249 (1974) 6657-6667.

[28] Z. Otwinowski and W. Minor, Methods Enzymol. 276 (1997) 307-326.

[29] A.J. McCoy, R.W. Grosse-Kunstleve, P.D. Adams, M.D. Winn, L.C. Storoni, R.J. Read, J. Appl. Crystallogr. 40 (2007) 658-674.

[30] G.N. Murshudov, A.A. Vagin, E.J. Dodson, Acta Crystallogr. D Biol. Crystallogr. 53 (1997) 240-255.

[31] M.D. Winn, M.N. Isupov, G.N. Murshudov, Acta Crystallogr. D Biol. Crystallogr. 57 (2001) 122-133.

[32] M.D. Winn, G.N. Murshudov, M.Z. Papiz, Methods Enzymol. 374 (2003) 300-321.

[33] P. Emsley and K. Cowtan, Acta Crystallogr. D Biol. Crystallogr. 60 (2004) 2126-2132.

[34] G.L. Waldrop, I. Rayment, H.M. Holden, Biochemistry 33 (1994) 10249-10256.

[35] C.Z. Blanchard, Y.M. Lee, P.A. Frantom, G.L. Waldrop, Biochemistry 38 (1999) 33933400 .

[36] K.L. Levert, R.B. Lloyd, G.L. Waldrop, Biochemistry 39 (2000) 4122-4128.

[37] T.N. Zeczycki, A.L. Menefee, A. Adina-Zada, S. Jitrapakdee, K.H. Surinya, J.C. Wallace, P.V. Attwood, M. St Maurice, W.W. Cleland, Biochemistry (2011) 9724-9737.

[38] C.Y. Chou, L.P. Yu, L. Tong, J. Biol. Chem. 284 (2009) 11690-11697.

[39] R.B. Guchhait, S.E. Polakis, P. Dimroth, E. Stoll, J. Moss, M.D. Lane, J. Biol. Chem. 249 (1974) 6633-6645.

[40] C.Z. Blanchard, A. Chapman-Smith, J.C. Wallace, G.L. Waldrop, J. Biol. Chem. 274 (1999) 31767-31769.

[41] C.Z. Blanchard and G.L. Waldrop, J. Biol. Chem. 273 (1998) 19140-19145.

[42] L.P. Yu, S. Xiang, G. Lasso, D. Gil, M. Valle, L. Tong, Structure 17 (2009) 823-832.

[43] T.N. Zeczycki, A.L. Menefee, S. Jitrapakdee, J.C. Wallace, P.V. Attwood, M. St Maurice, W.W. Cleland, Biochemistry (2011) 9694-9707.

[44] I.H. Segel, Enzyme Kinetics. Behavior and Analysis of Rapid-Equilibrium and Steady-State Enzyme Systems, John Wiley \& Sons, New York, NY, 1975.

[45] T.W. Lin, M.M. Melgar, D. Kurth, S.J. Swamidass, J. Purdon, T. Tseng, G. Gago, P. Baldi, H. Gramajo, S.C. Tsai, Proc. Natl. Acad. Sci. U. S. A. 103 (2006) 3072-3077.

[46] S. Jitrapakdee, M. St Maurice, I. Rayment, W.W. Cleland, J.C. Wallace, P.V. Attwood, Biochem. J. 413 (2008) 369-387.

[47] I. Mochalkin, J.R. Miller, A. Evdokimov, S. Lightle, C. Yan, C.K. Stover, G.L. Waldrop, Protein Sci. 17 (2008) 1706-1718.

[48] P.V. Attwood and J.C. Wallace, Biochem. J. 235 (1986) 359-364.

[49] M.C. Scrutton and A.S. Mildvan, Biochemistry 7 (1968) 1490-1505.

[50] D.C. Fry, T.L. Fox, M.D. Lane, A.S. Mildvan, J. Am. Chem. Soc. 107 (1985) 7659 - 7665. 
[51] B.C. Narayanan, W. Niu, Y. Han, J. Zou, P.S. Mariano, D. Dunaway-Mariano, O. Herzberg, Biochemistry 47 (2008) 167-182.

[52] M. Di Berardino and P. Dimroth, Eur. J. Biochem. 231 (1995) 790-801. 


\section{TABLES}

Table 1. Data Collection and Refinement Statistics

\begin{tabular}{|c|c|c|}
\hline & $\begin{array}{c}\Delta \mathrm{BC} \Delta \mathrm{BCCP} \operatorname{Re} \mathrm{PC}+ \\
\text { oxamate }+ \text { biotin }\end{array}$ & $\begin{array}{l}\Delta \mathrm{BC} \triangle \mathrm{BCCP} R e \mathrm{PC}+ \\
\text { pyruvate + biocytin }\end{array}$ \\
\hline PDB ID code & $4 \mathrm{LOC}$ & $4 \mathrm{M} 6 \mathrm{~V}$ \\
\hline Space Group & $P 2_{1} 2_{1} 2_{1}$ & $P 2_{1} 2_{1} 2_{1}$ \\
\hline \multicolumn{3}{|l|}{$\begin{array}{c}\text { Cell Dimensions } \\
\quad a, b, c(\AA)\end{array}$} \\
\hline \multirow[t]{2}{*}{$\alpha, \beta, \gamma\left({ }^{\circ}\right)$} & $84,157,245$ & $85,158,245$ \\
\hline & $90,90,90$ & $90,90,90$ \\
\hline Resolution range, $\AA$ & $\begin{array}{l}50.0-2.26 \\
(2.30-2.26)^{a}\end{array}$ & $\begin{array}{l}50.0-2.40 \\
(2.44-2.40)^{\mathrm{a}}\end{array}$ \\
\hline Redundancy & $7.1(6.8)$ & $7.2(7.1)$ \\
\hline Completeness (\%) & $98.3(94.7)$ & $99.8(99.8)$ \\
\hline Unique Reflections & 145868 & 128103 \\
\hline $\mathrm{R}_{\text {merge }}(\%)$ & $8.4(44.4)$ & $6.9(40.5)$ \\
\hline Average $\mathrm{I} / \sigma \mathrm{I}$ & $20.6(3.4)$ & $25.7(5.2)$ \\
\hline \multicolumn{3}{|l|}{ Refinement: } \\
\hline Resolution range, $\AA$ & $\begin{array}{l}43.75-2.26 \\
(2.32-2.26)\end{array}$ & $\begin{array}{l}49.66-2.40 \\
(2.46-2.40)\end{array}$ \\
\hline $\mathrm{R}_{\text {cryst }}$ & $0.176(0.227)$ & $0.184(0.245)$ \\
\hline$R_{\text {free }}$ & $0.216(0.293)$ & $0.223(0.301)$ \\
\hline No. protein atoms & 17924 & 17894 \\
\hline No. water molecules & 535 & 361 \\
\hline Wilson B-value $\left(\AA^{2}\right)$ & 34.4 & 45.4 \\
\hline \multicolumn{3}{|l|}{ Average B-factors $\left(\AA^{2}\right)$} \\
\hline Protein & 52.8 & 65.1 \\
\hline Ligands & 57.4 & 65.5 \\
\hline Solvent & 41.5 & 51.1 \\
\hline \multicolumn{3}{|l|}{ Ramachandran (\%) } \\
\hline Most favored & 92.2 & 92.7 \\
\hline Additionally allowed & 7.3 & 7.0 \\
\hline Generously allowed & 0.5 & 0.3 \\
\hline Disallowed & 0.0 & 0.0 \\
\hline \multicolumn{3}{|l|}{ r.m.s. deviations } \\
\hline Bond lengths $(\AA)$ & 0.018 & 0.011 \\
\hline Bond angles $\left({ }^{\circ}\right)$ & 1.836 & 1.385 \\
\hline
\end{tabular}


Table 2. Effects of free biotin, biocytin and ReBCCP on the decarboxylation of oxaloacetate by pyruvate carboxylase and pyruvate carboxylase variants. ${ }^{a}$

\begin{tabular}{|c|c|c|c|c|}
\hline & $\begin{array}{l}1 \mathrm{mM} \\
\text { oxaloacetate, } \\
k_{\text {cat }}\left(\mathrm{min}^{-1}\right)\end{array}$ & $\begin{array}{l}+5 \mathrm{mM} \text { biotin, } \\
k_{\mathrm{cat}}\left(\mathrm{min}^{-1}\right)\end{array}$ & $\begin{array}{l}+5 \mathrm{mM} \\
\text { biocytin, } k_{\text {cat }} \\
\left(\mathrm{min}^{-1}\right)\end{array}$ & $\begin{array}{l}+1000 \times \text { molar } \\
\text { excess } \\
R e \mathrm{BCCP}^{b}, k_{\mathrm{cat}} \\
\left(\mathrm{min}^{-1}\right)\end{array}$ \\
\hline$R e \mathrm{PC}$ wt & $1.23 \pm 0.01$ & $2.2 \pm 0.1$ & $4.0 \pm 0.1$ & $76.0 \pm 0.4$ \\
\hline K1119Q $\operatorname{RePC}$ & $1.05 \pm 0.02$ & $1.90 \pm 0.02$ & $3.95 \pm 0.05$ & $94.4 \pm 4.5$ \\
\hline$\Delta \mathrm{BC} R e \mathrm{PC}$ & $0.51 \pm 0.02$ & $0.87 \pm 0.03$ & $1.62 \pm 0.04$ & $39.1 \pm 0.8$ \\
\hline $\begin{array}{l}\text { K1119Q } \Delta \mathrm{BC} \\
\operatorname{RePC}\end{array}$ & $0.37 \pm 0.01$ & $0.75 \pm 0.01$ & $1.43 \pm 0.03$ & $35.3 \pm 0.9$ \\
\hline $\begin{array}{l}\Delta \mathrm{BC} \triangle \mathrm{BCCP} \\
\operatorname{Re} \mathrm{PC}\end{array}$ & $0.46 \pm 0.01$ & $0.88 \pm 0.01$ & $2.56 \pm 0.01$ & $50.9 \pm 3.9$ \\
\hline \multicolumn{5}{|c|}{$\begin{array}{l}{ }^{a} \text { Reaction conditions: } 100 \mathrm{mM} \text { Tris- } \mathrm{HCl}(\mathrm{pH} 7.8), 30^{\circ} \mathrm{C}, 1 \mathrm{mM} \text { oxaloacetate, } 0.25 \mathrm{mM} \\
\text { acetyl-CoA (RePC wt and } \mathrm{K} 1119 \mathrm{Q} R e \mathrm{PC} \text { only), } 0.24 \mathrm{mM} \mathrm{NADH} \text {. Specific activities } \\
\text { were determined in triplicate and the reported errors are standard deviations of the means. } \\
{ }^{b} R e \mathrm{BCCP} \text { was assayed as a substrate at } 1000 \text {-fold molar excess over the enzyme } \\
\text { concentration. This ranged from } 60 \text { to } 70 \mu \mathrm{M} \text {, depending on the enzyme concentration }\end{array}$} \\
\hline
\end{tabular}

Table 3. Oxaloacetate decarboxylation activities in the presence and absence of oxamate for pyruvate carboxylase and pyruvate carboxylase variants. ${ }^{a}$

\begin{tabular}{|c|c|c|}
\hline & $\begin{array}{l}0.2 \mathrm{mM} \text { oxaloacetate, } k_{\text {cat }} \\
\left(\mathrm{min}^{-1}\right)\end{array}$ & $\begin{array}{l}+0.5 \mathrm{mM} \text { oxamate, } k_{\mathrm{cat}} \\
\left(\mathrm{min}^{-1}\right)\end{array}$ \\
\hline$R e \mathrm{PC}$ wt & $1.29 \pm 0.02$ & $3.8 \pm 0.2$ \\
\hline K1119Q RePC & $0.83 \pm 0.02$ & $0.83 \pm 0.03$ \\
\hline$\Delta \mathrm{BC} R e \mathrm{PC}$ & $0.53 \pm 0.01$ & $10.2 \pm 0.3$ \\
\hline $\mathrm{K} 1119 \mathrm{Q} \Delta \mathrm{BC} R e \mathrm{PC}$ & $0.33 \pm 0.01$ & $0.35 \pm 0.03$ \\
\hline$\Delta \mathrm{BC} \Delta \mathrm{BCCP} R e \mathrm{PC}$ & $0.45 \pm 0.01$ & $0.38 \pm 0.03$ \\
\hline \multicolumn{3}{|c|}{$\begin{array}{l}{ }^{a} \text { Reaction conditions: } 100 \mathrm{mM} \text { Tris- } \mathrm{HCl}(\mathrm{pH} 7.8), 30^{\circ} \mathrm{C}, 0.2 \mathrm{mM} \text { oxaloacetate, } 0.25 \mathrm{mM} \\
\text { acetyl-CoA (RePC wt and } \mathrm{K} 1119 \mathrm{Q} \mathrm{Re} \mathrm{PC} \text { only), } 0.24 \mathrm{mM} \mathrm{NADH} \text {. Specific activities } \\
\text { were determined in triplicate and the reported errors are standard deviations of the means. } \\
\text { Acetyl-CoA does not affect the catalytic rate of oxaloacetate decarboxylation when the } \\
\mathrm{BC} \text { domain is removed (data not shown). }\end{array}$} \\
\hline
\end{tabular}




\section{SCHEMES.}

\section{Scheme 1.}
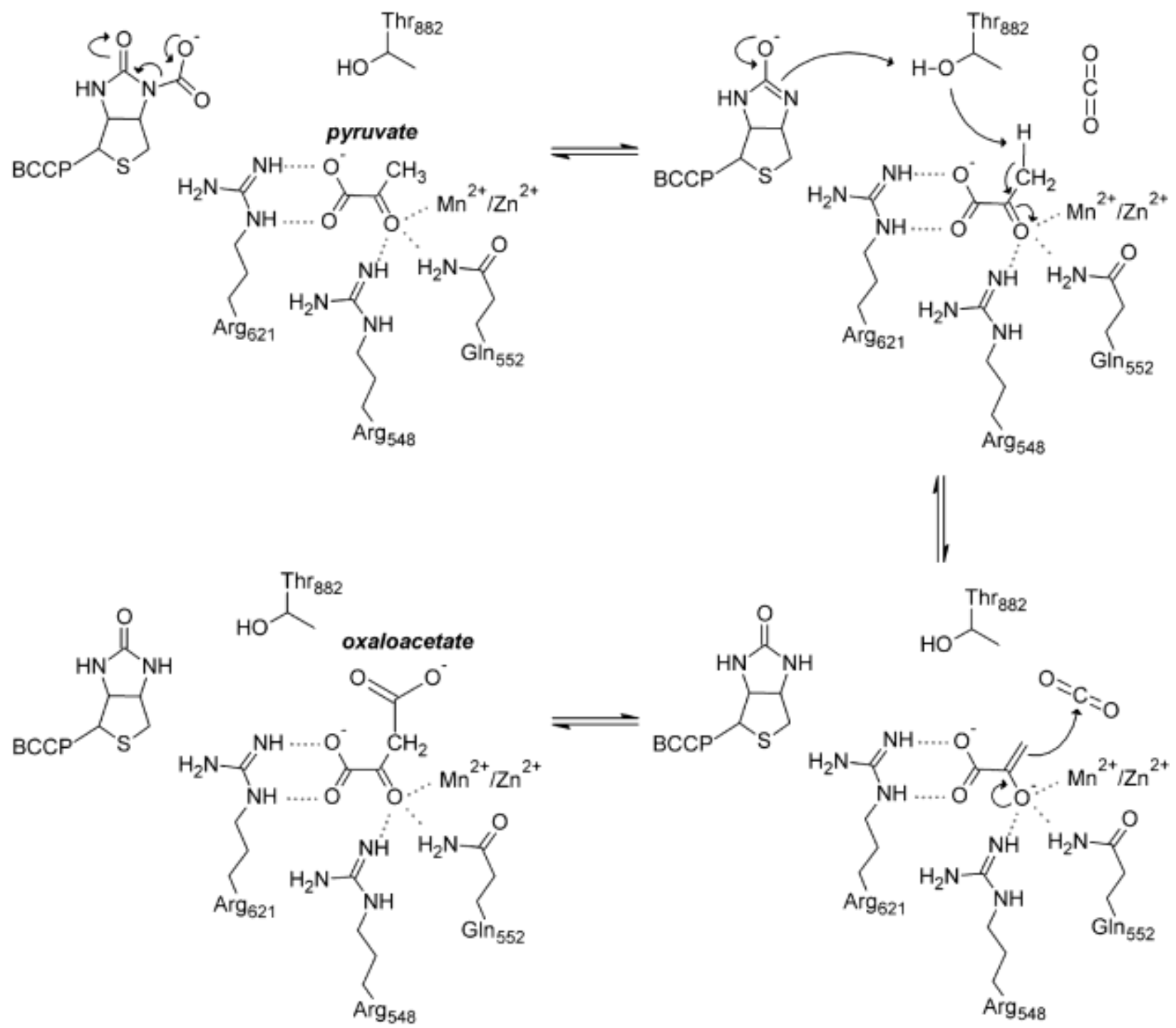


\section{Scheme 2.}

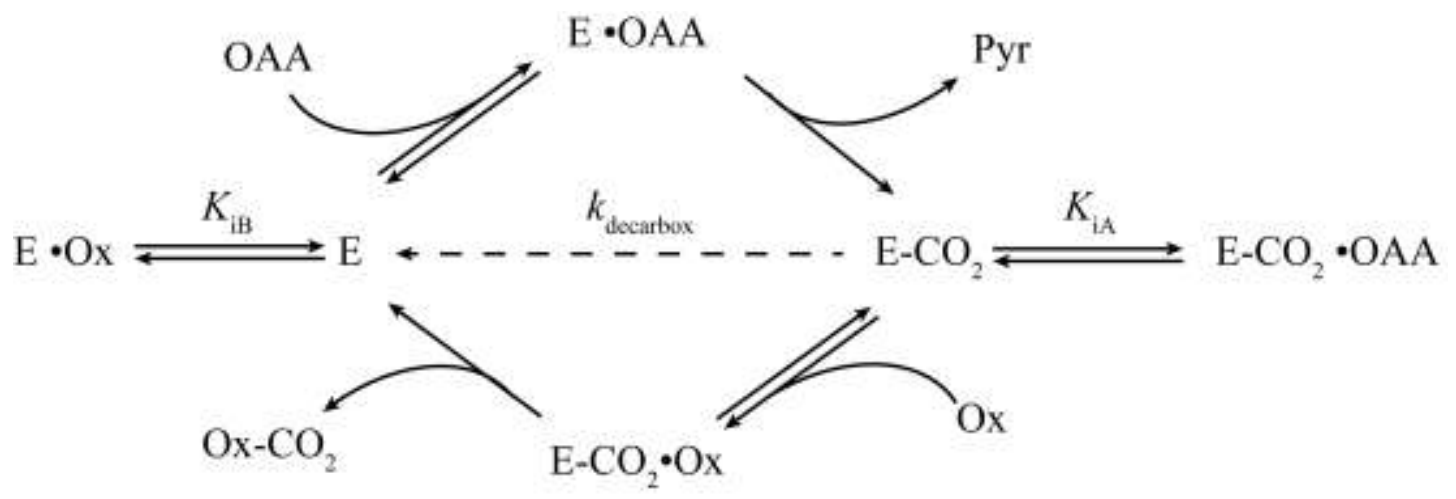

\section{Scheme 3.}
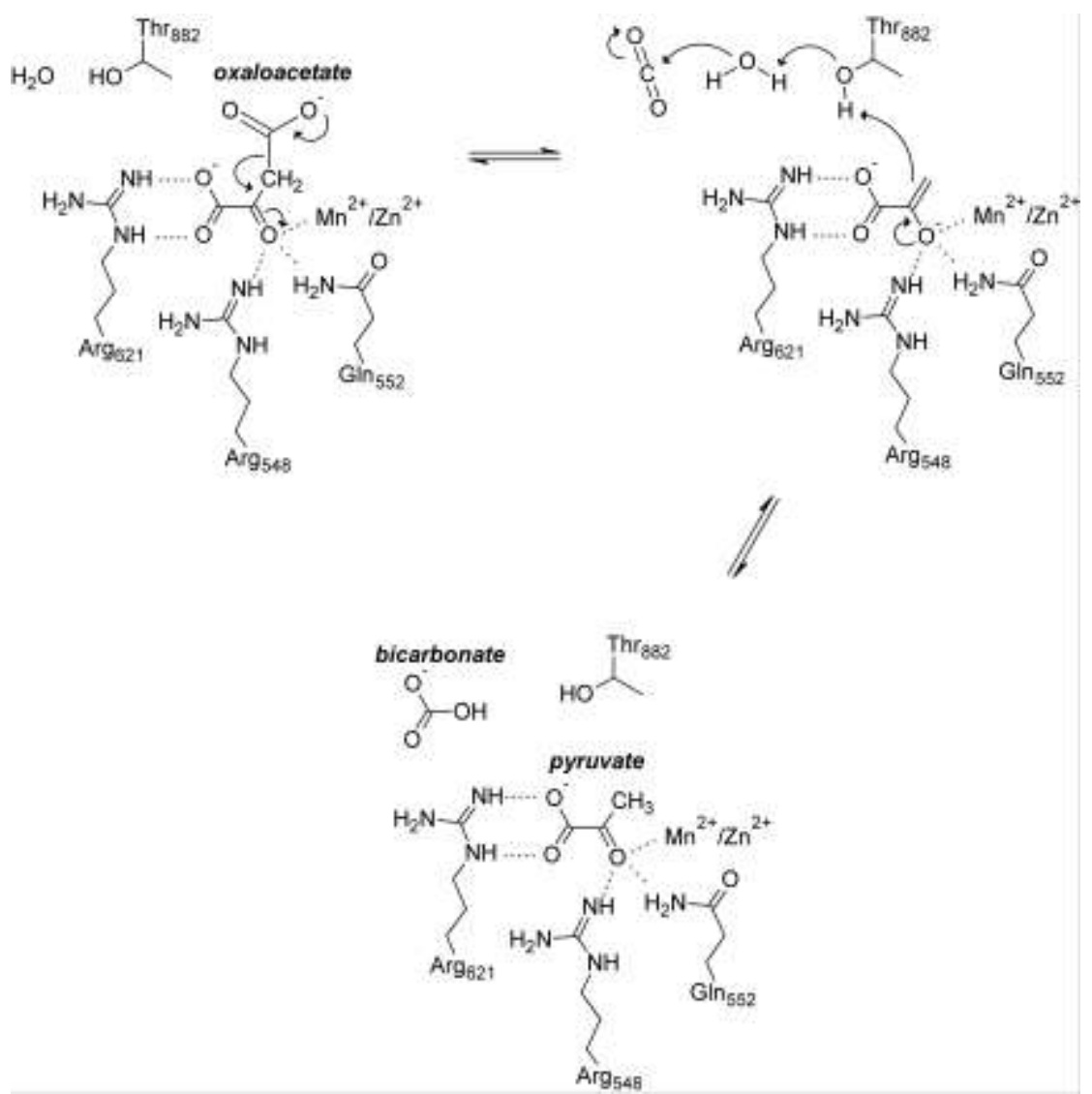


\section{FIGURE LEGENDS.}

Figure 1. Primary sequence of Rhizobium etli pyruvate carboxylase $(R e P C)$ and the truncated constructs utilized in this study. The amino acid numbers designate the boundaries for the various functional domains of $R e \mathrm{PC}$.

Figure 2. Representative simulated annealing omit maps for oxamate (A) and pyruvate (B) in the active site of $\triangle \mathrm{BC} \triangle \mathrm{BCCP} R e \mathrm{PC}$. The electron density maps are contoured to $3.0 \sigma$. Oxamate and pyruvate are colored green and yellow, respectively.

Figure 3. A double reciprocal plot of initial velocity versus substrate concentration for the $\triangle \mathrm{BC}$ $R e \mathrm{PC}$ catalyzed decarboxylation of oxaloacetate at fixed concentrations of oxamate $(0.1 \mathrm{mM}$, circles; $0.3 \mathrm{mM}$, triangles; $1.0 \mathrm{mM}$, squares; $5.0 \mathrm{mM}$, diamonds). Solid lines are the calculated individual fits of the data to the reciprocal of [eq 1]. INSET: The initial velocity normalized for enzyme concentration $\left(v_{i} /[\mathrm{E}]_{\mathrm{T}}\right)$ as a function of low concentrations of oxaloacetate. Unlike the full-length enzyme [17], the curves do not display any sigmoidicity. The oxamate concentrations are designated in the same way as for the double reciprocal plot and the curve fits are calculated from [eq 1].

Figure 4. Free biocytin (magenta, CPK coloring), co-crystallized with pyruvate (orange, CPK coloring), is bound in the funnel of the carboxyltransferase (CT) domain (cyan) leading to the active site. The BCCP domain and biotin (green) are shown from a structural superposition of the $\mathrm{CT}$ domain of $H s \mathrm{PC}$ (pdb i.d. 3BG3). The interaction between the BCCP and $\mathrm{CT}$ domain results in the inward rotation of $\alpha$-helix 10, which threads away from the active site (yellow). The binding of biocytin in the funnel does not induce this same rotation in $\alpha$-helix 10 . 


\section{FIGURES}

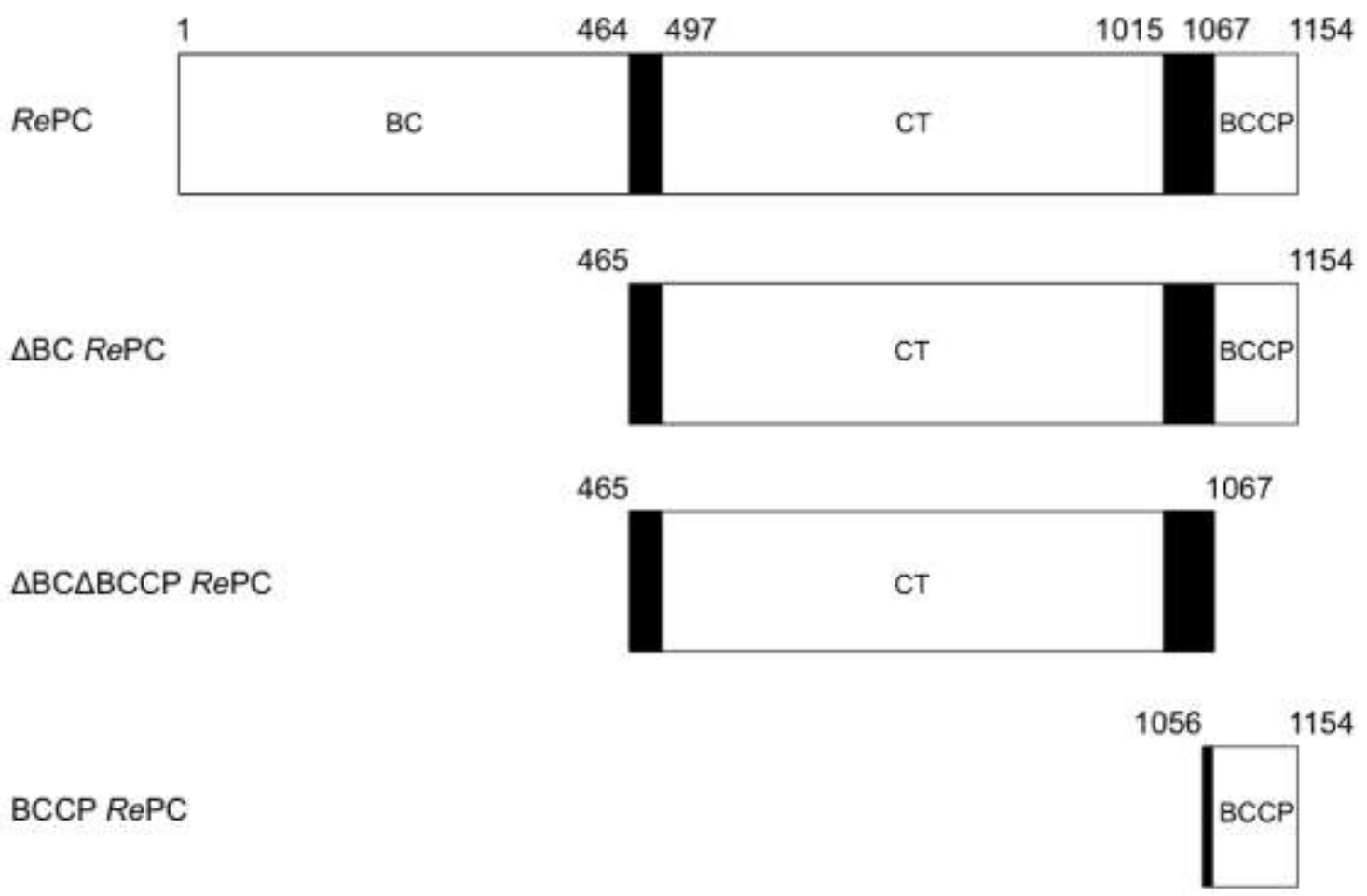

Figure 1 


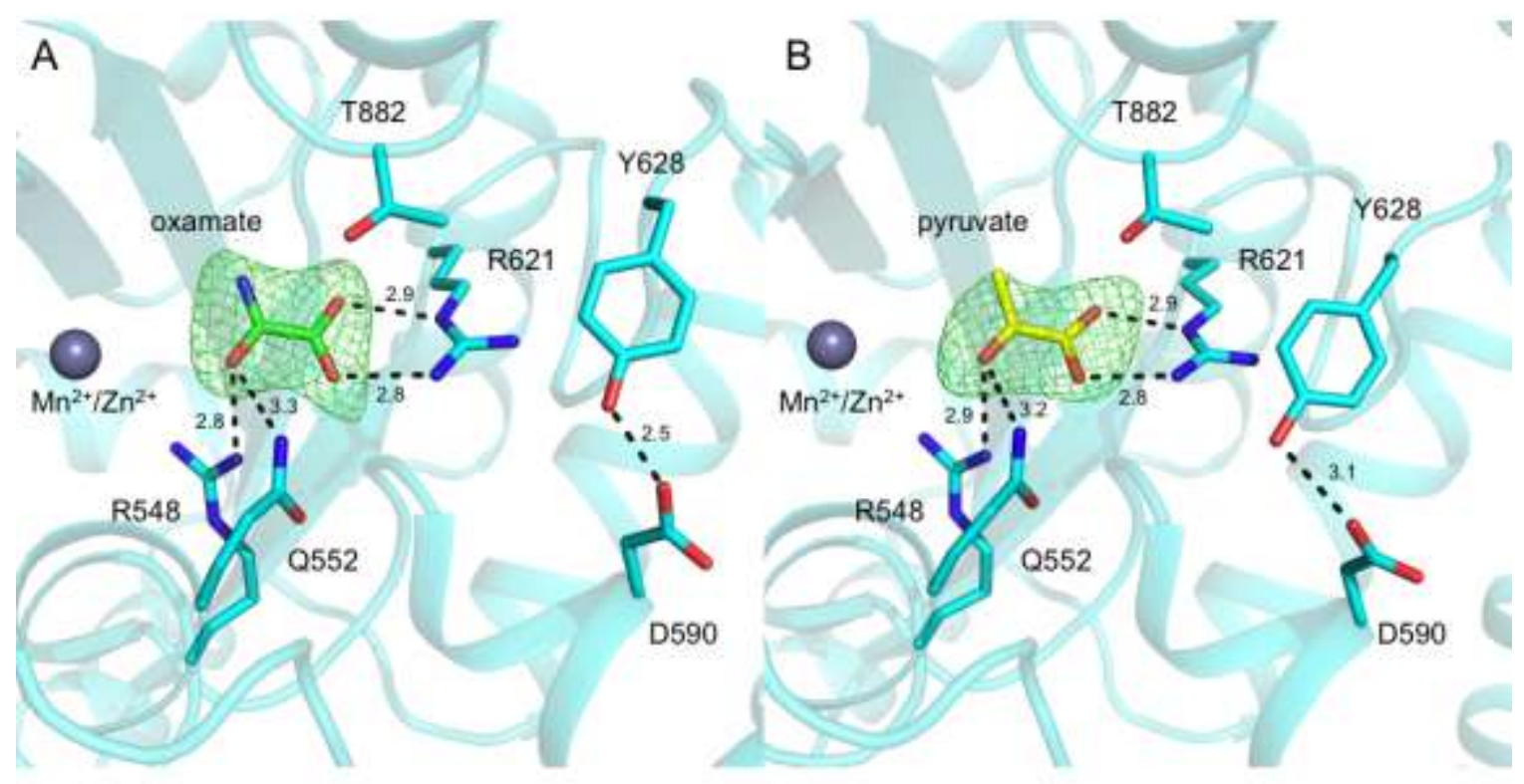

Figure 2 


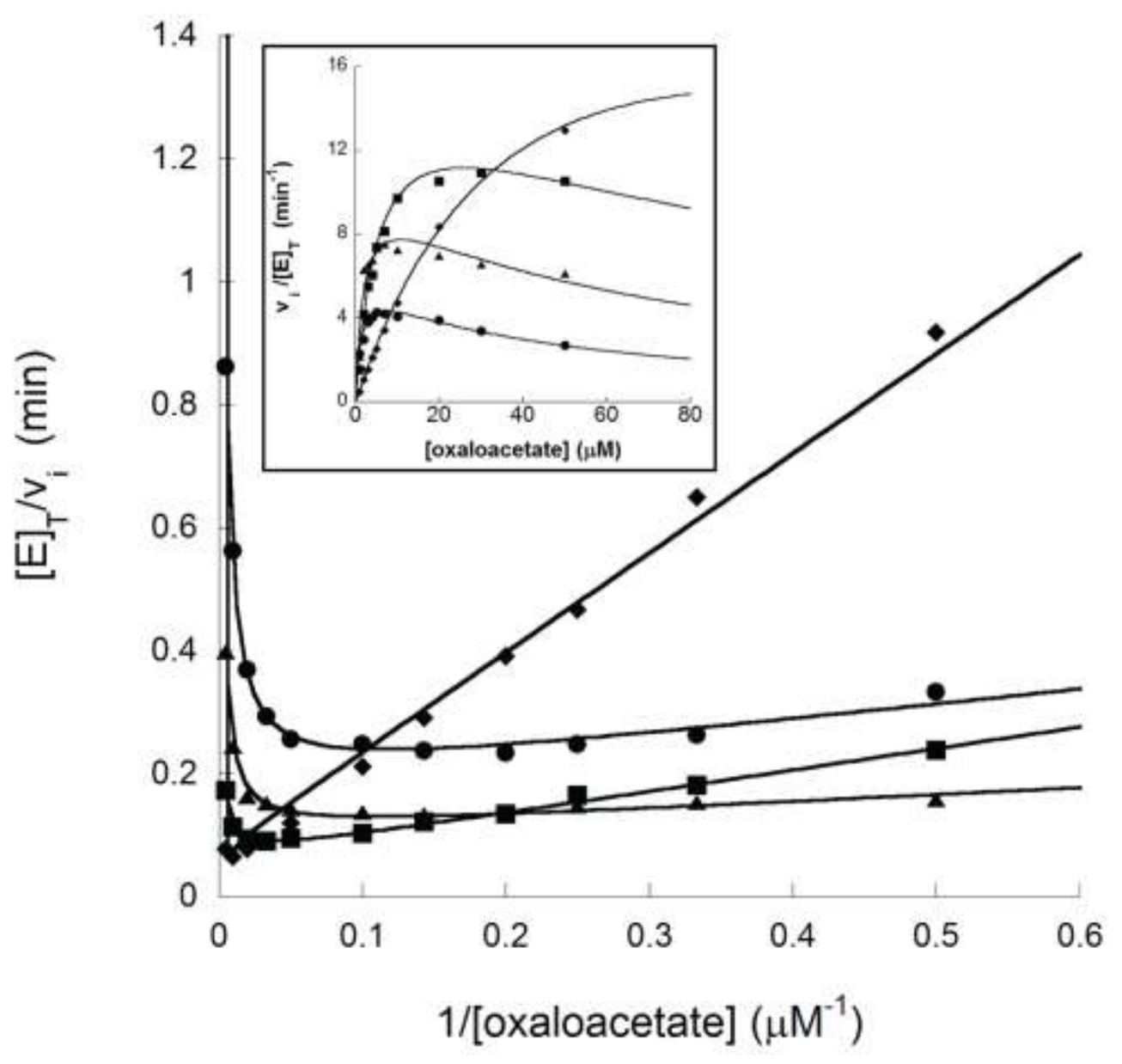

Figure 3. 


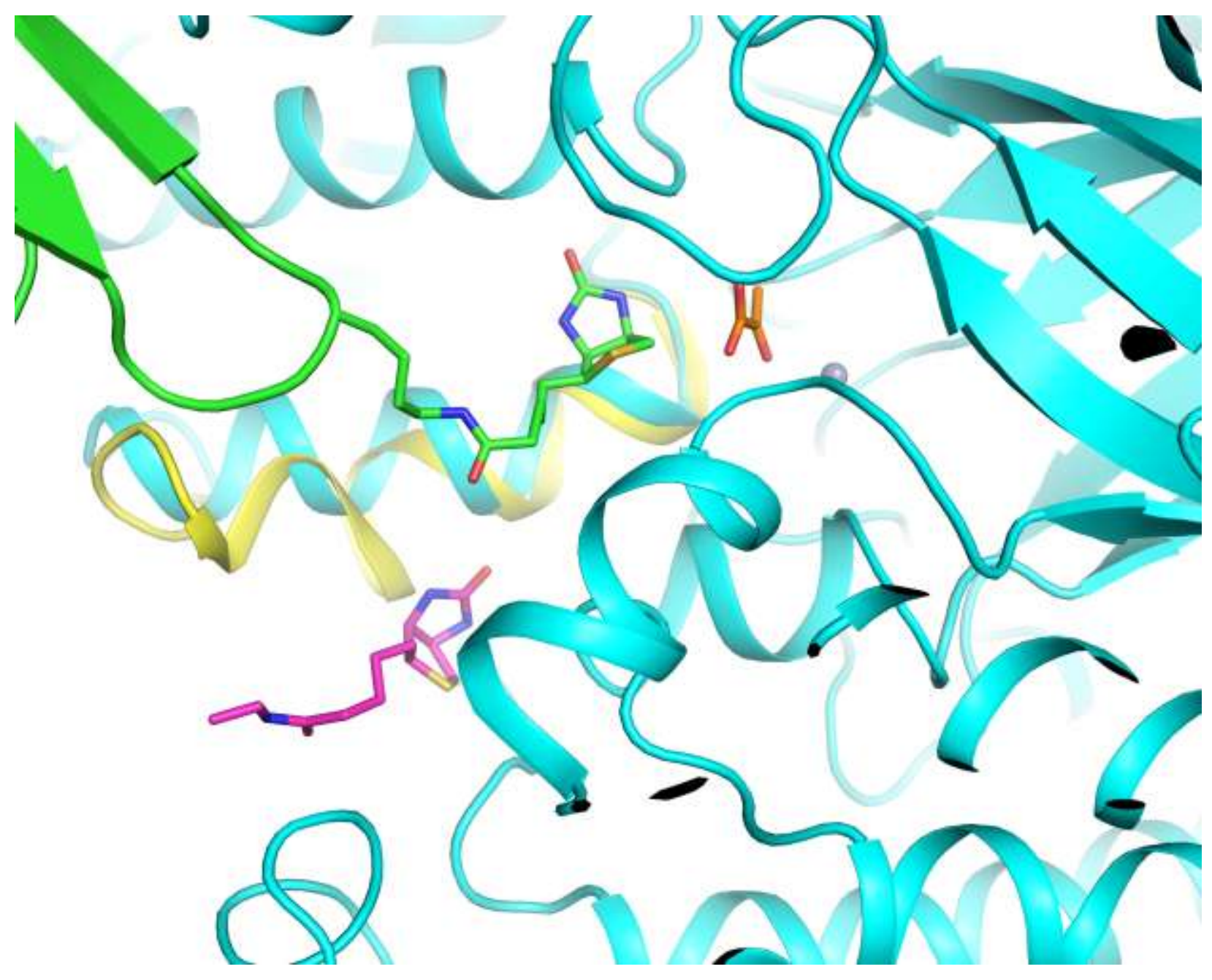

Figure 4 